\title{
Subaxial Vertebral Artery Rotational Occlusion Syndrome: An Overview of Clinical Aspects, Diagnostic Work-Up, and Surgical Management
}

\author{
Sabino Luzzi ${ }^{1,2}$, Cristian Gragnaniello ${ }^{3}$, Stefano Marasco ${ }^{1}$, Alice Giotta Lucifero ${ }^{1}$, \\ Mattia Del Maestro ${ }^{2,4}$, Giuseppe Bellantoni ${ }^{2}$, Renato Galzio ${ }^{5}$ \\ ${ }^{I}$ Neurosurgery Unit, Department of Clinical-Surgical, Diagnostic and Pediatric Sciences, University of Pavia, Pavia, Italy \\ ${ }^{2}$ Neurosurgery Unit, Department of Surgical Sciences, Fondazione IRCCS Policlinico San Matteo, Pavia, Italy \\ ${ }^{3}$ Department of Neurological Surgery, University of Illinois at Chicago, Chicago, IL, USA \\ ${ }^{4} \mathrm{PhD}$ School in Experimental Medicine, Department of Clinical-Surgical, Diagnostic and Pediatric Sciences, University of Pavia, Pavia, Italy \\ ${ }^{5}$ Neurosurgery Unit, Maria Cecilia Hospital, Cotignola, Italy
}

\begin{abstract}
Extrinsic compression of the subaxial vertebral artery (VA) may cause rotational occlusion syndrome (ROS) and contribute to vertebrobasilar insufficiency potentially leading to symptoms and in severe cases, to posterior circulation strokes. The present literature review aimed to report the main clinical findings, diagnostic work-up, and surgical management of the subaxial VA-ROS, the diagnosis of which can be difficult and is often underestimated. An illustrative case is also presented. A thorough literature search was conducted to retrieve manuscripts that have discussed the etiology, diagnosis, and treatment of ROS. Total 41 articles were selected based on the best match and relevance and mainly involved case reports and small cases series. The male/female ratio and average age were 2.6 and $55.6 \pm 11$ years, respectively. Dizziness, visual disturbances, and syncope were the most frequent symptoms in order of frequency, while C5 and C6 were the most affected levels. Osteophytes were the cause in $>46.2 \%$ of cases. Dynamic VA catheterbased angiography was the gold standard for diagnosis along with computed tomography angiography. Except in older patients and those with prohibitive comorbidities, anterior decompressive surgery was always performed, mostly with complete recovery, and zero morbidity and mortality. A careful neurological evaluation and dynamic angiographic studies are crucial for the diagnosis of subaxial VA-ROS. Anterior decompression of the VA is the cure of this syndrome in almost all cases.
\end{abstract}

Keywords: Cerebral angiography; Posterior circulation; Spondylosis; Stroke; Vertebral artery; Vertebrobasilar insufficiency

\section{Introduction}

Subaxial vertebral artery (VA) rotational occlusion syndrome (ROS) causes a transient or permanent decrease in blood flow in the posterior cerebral circulation that is associated with the occurrence of dizziness, drop attacks, visual disturbances, sensitive and motor symptoms, and even devastating strokes. These symptoms are classically triggered by the axial rotation of the head within the physiologic range of motion [1].

Disk herniation, spondylosis, ligamentous hypertrophy, bony defects, and abnormalities in the course of the VA

\footnotetext{
Received Jun 1, 2020; Revised Jun 23, 2020; Accepted Jul 1, 2020

Corresponding author: Sabino Luzzi

Neurosurgery Unit, Department of Clinical-Surgical, Diagnostic and Pediatric Sciences, University of Pavia, Polo Didattico "Cesare Brusotti", Viale Brambilla, 74-27100, Pavia, Italy

Tel: +39-0382502780,+39-0382502781, Fax: +39-0382502267, E-mail: sabino.luzzi@unipv.it
} 


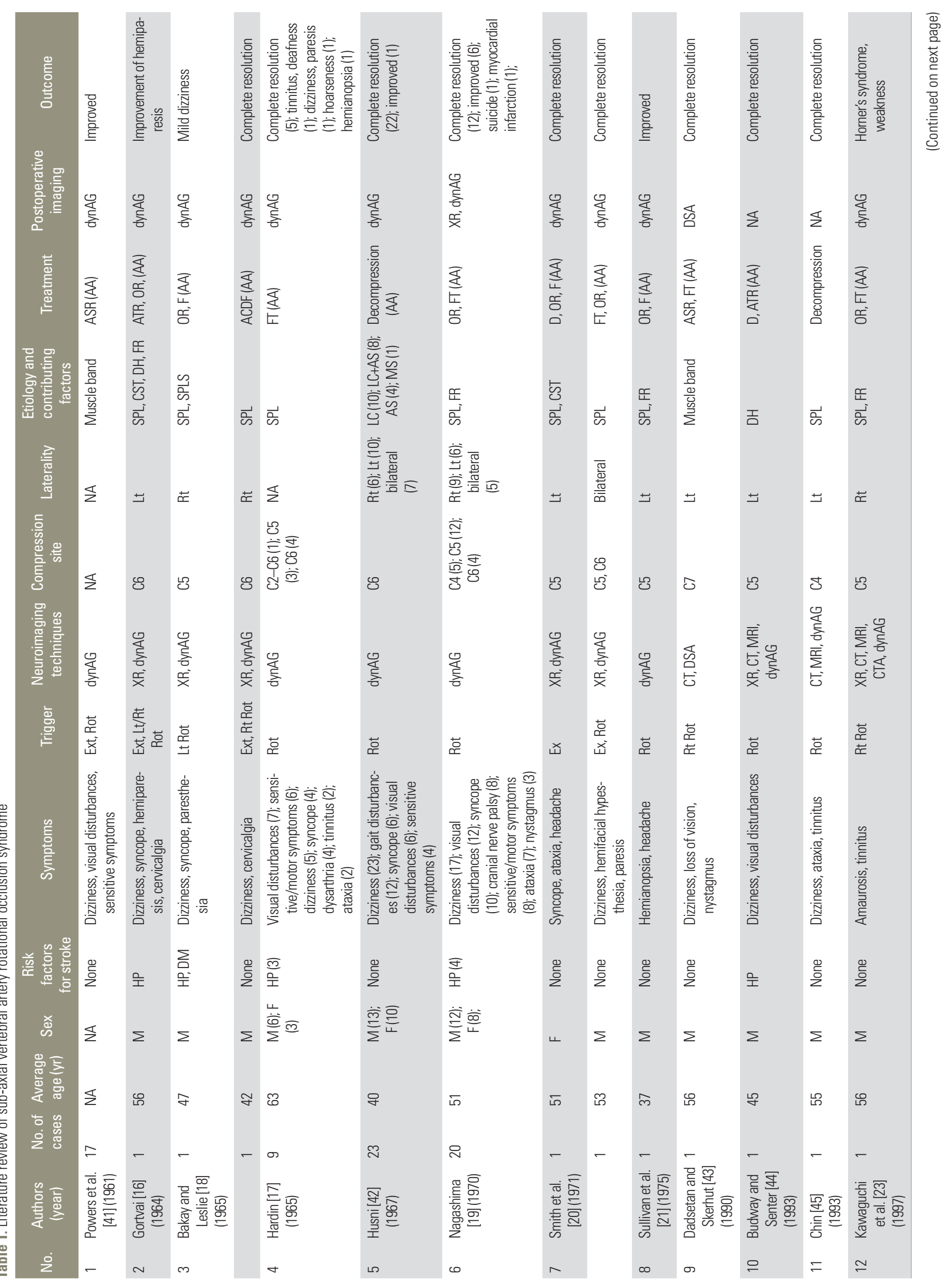



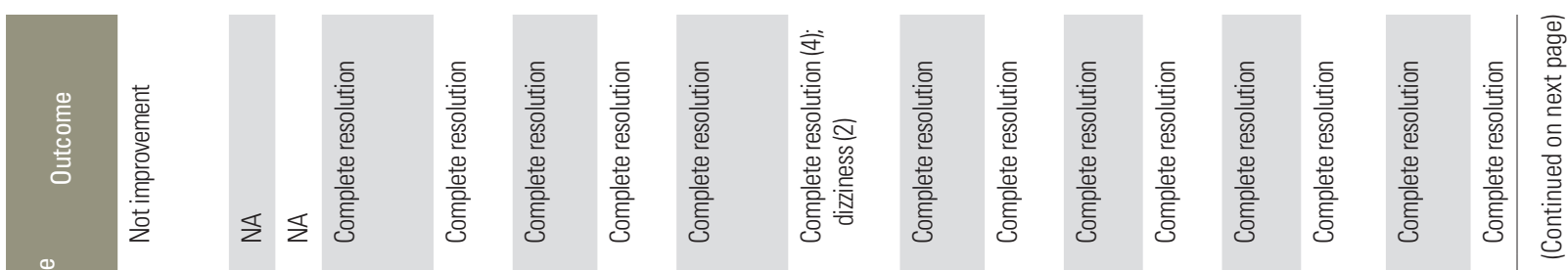

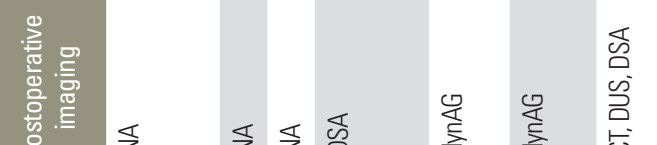

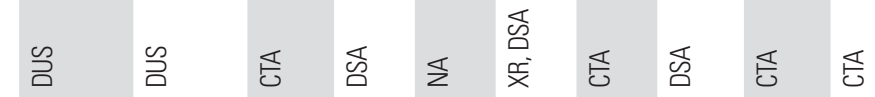

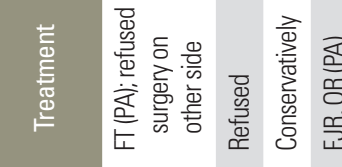

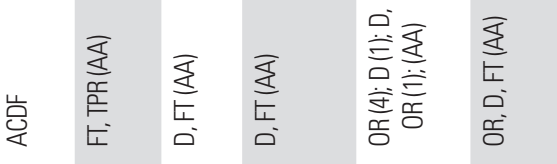

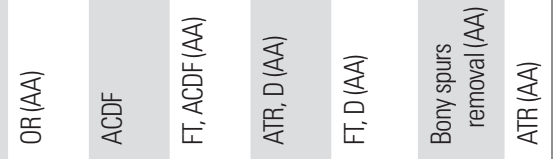

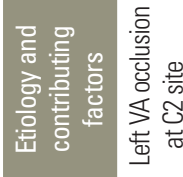

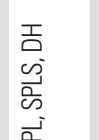

言言

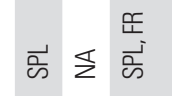

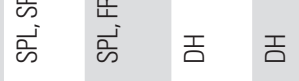

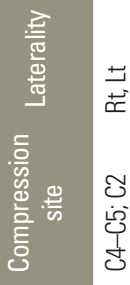
$\exists$ 茫

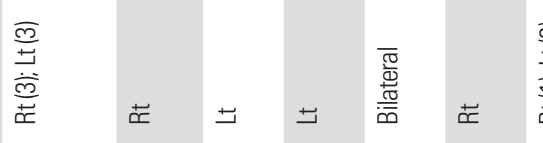

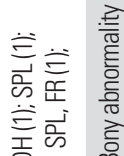

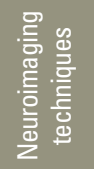

둥

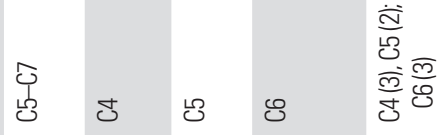

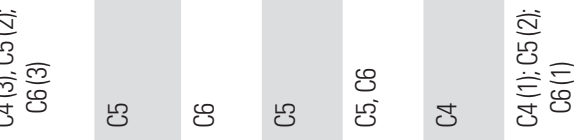

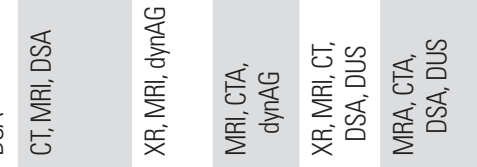

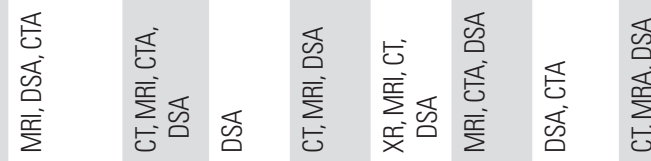

o o

离

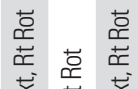

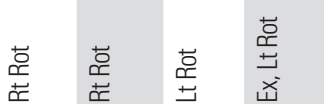

守产

京

䓍
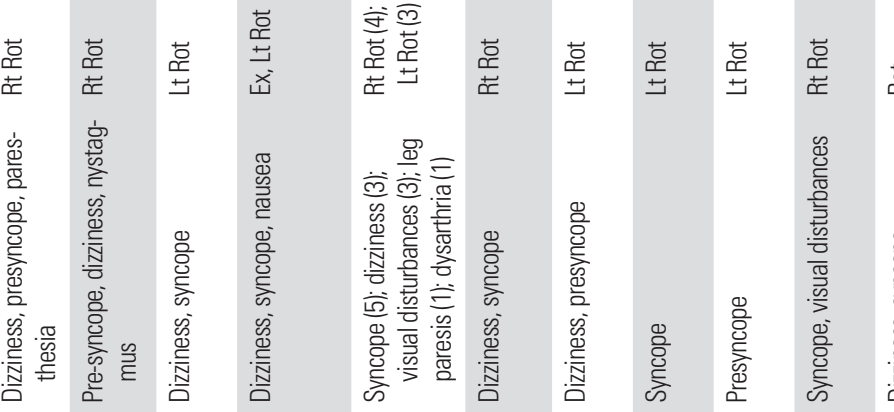

훙

荞

兹亭

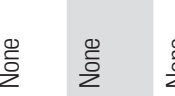

है

辛高

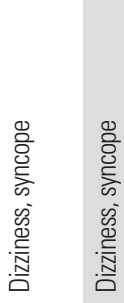

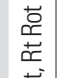




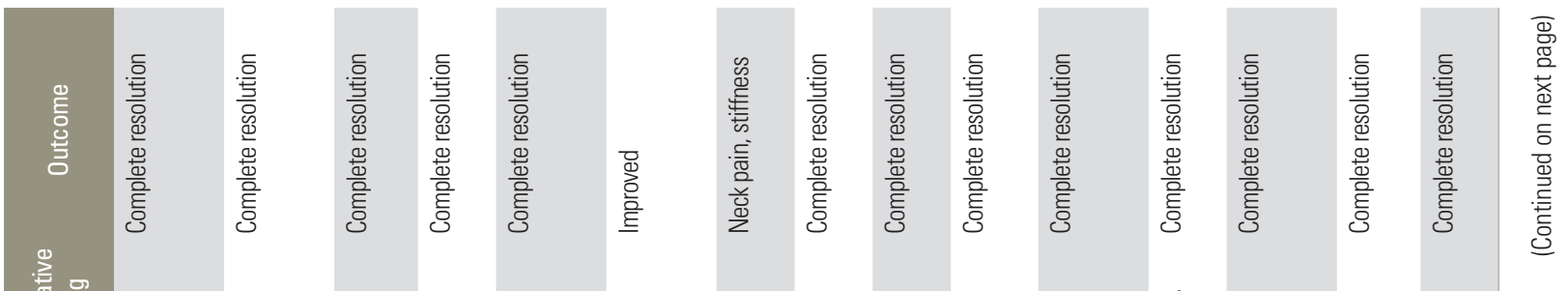

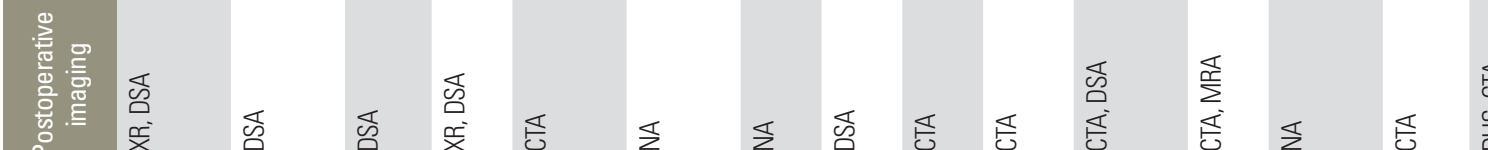

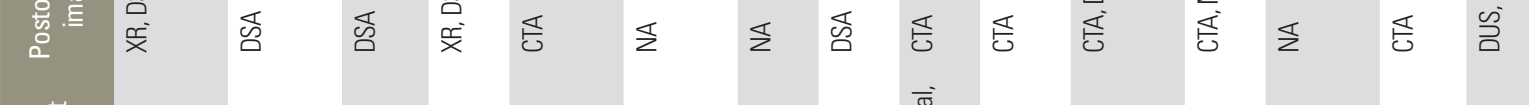

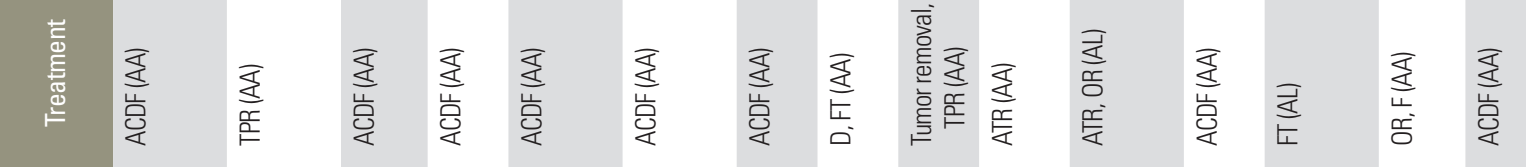

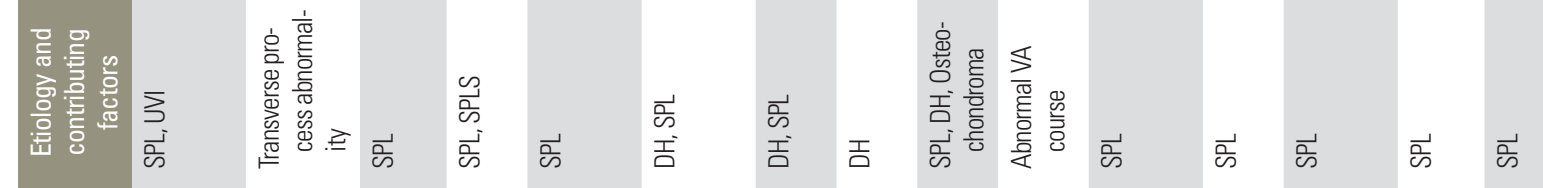

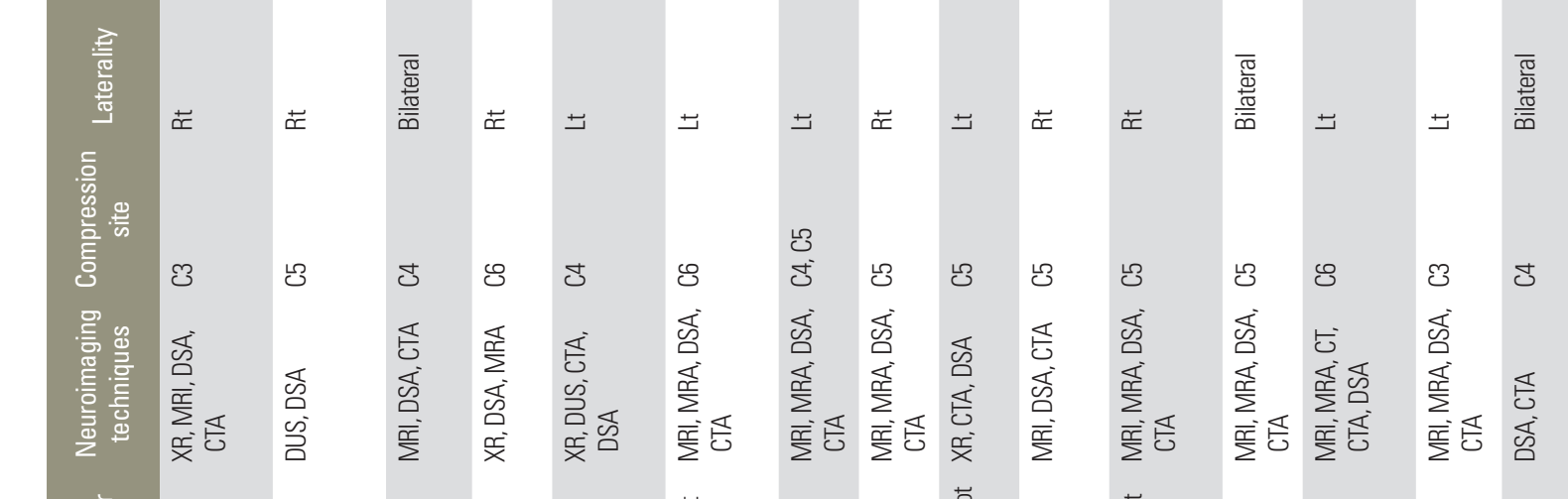

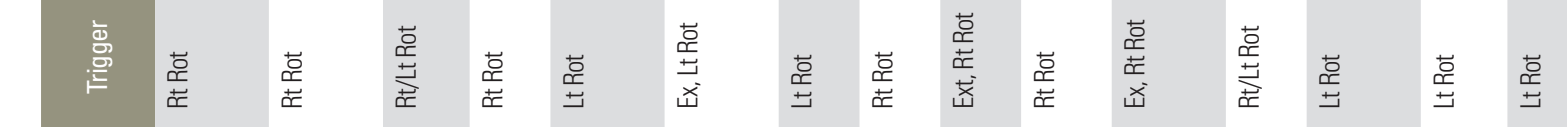

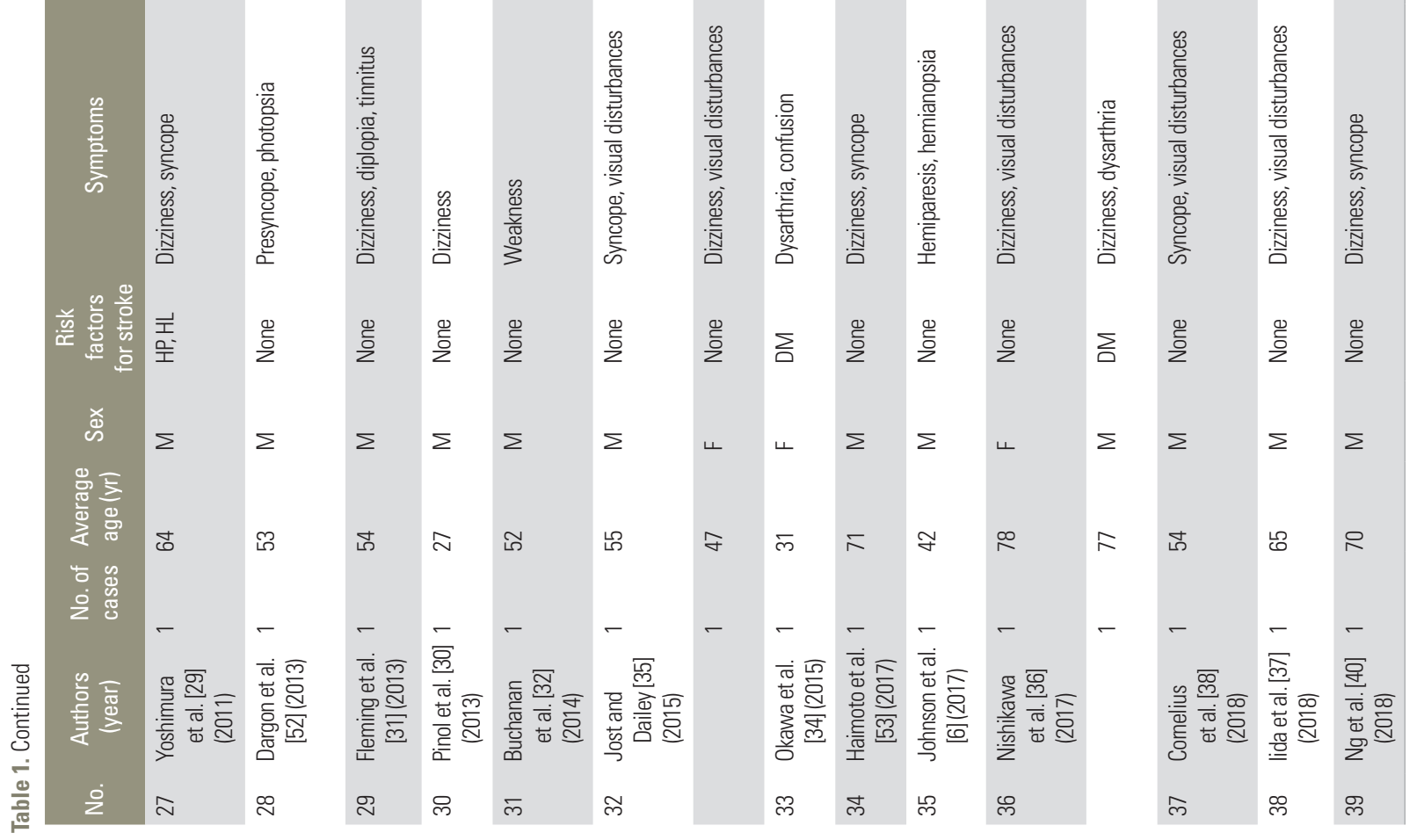




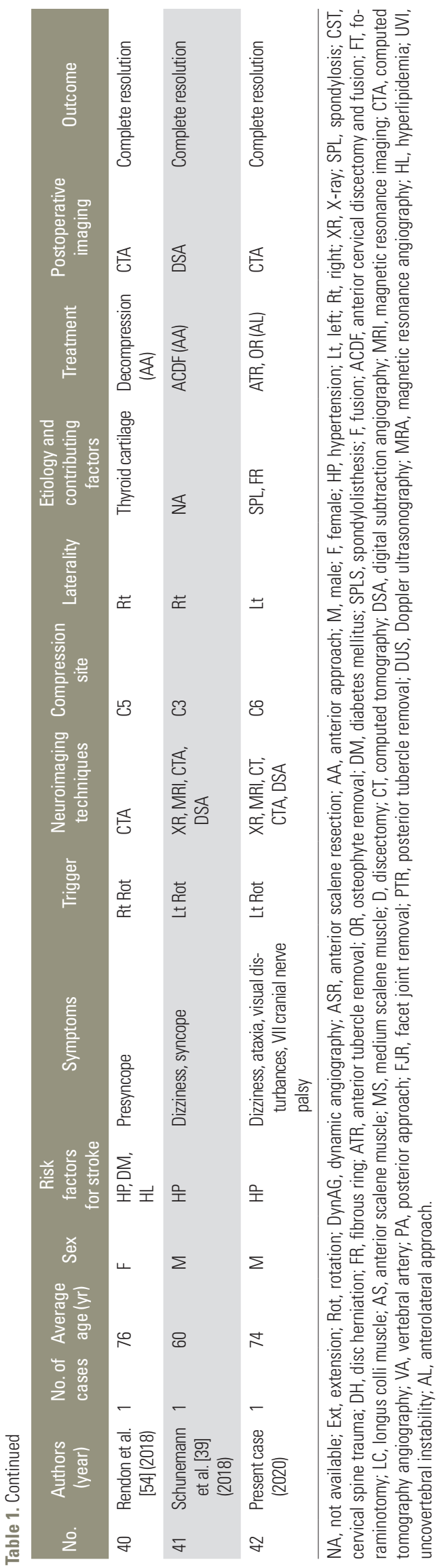

across the transverse foramina are the main etiological factors. Atherosclerosis worsens the frequency and severity of the symptoms [2-9]. The treatment of the subaxial VA-ROS is elective surgical that aims to decompress the VA and restore normal blood flow in the posterior circulation [10-15]. Nevertheless, literature about the overall management of this syndrome is limited and mostly consists of case reports or small case series [2,3,6,16-54].

This literature review addresses the clinical aspects, diagnosis, and surgical management of subaxial VA-ROS. An illustrative case is also reported.

\section{Methods}

Two separate systematic reviews of the literature were conducted using the Ovid Medline and EMBASE databases to identify articles relevant to the natural history, diagnosis methods, treatment modalities, and outcomes of patients affected by VA-ROS. A population, intervention, comparison, and outcome search strategy was used for each review. Keyword and MeSH search terms were used including "axis, cervical vertebra," "vertebral artery," "occlusion syndrome," "cervical vertebra," "compression syndrome," "bow hunter's syndrome," "decompression," "dynamic angiography," "vertebrobasilar insufficiency," and "head movements." All the manuscripts published in English were eligible for inclusion. This search strategy selected articles that described the diagnosis, natural history, and treatment of the VA-ROS. Reference lists of the included manuscripts were studied to identify additional relevant publications. Further articles were included following a manual search of the literature.

\section{Results}

\section{Literature volume}

The search retrieved 77 articles. After applying the exclusion criteria and removing duplicates, 41 relevant articles were selected and have been reported in Table 1.

\section{Demographic and clinical data}

Total 121 patients were included in the study. The male/ female ratio was 2.6 although sex was not reported in 24 patients. The average patient age was $55.6 \pm 11$ years, and those in the fifth decade were more affected. Graph 


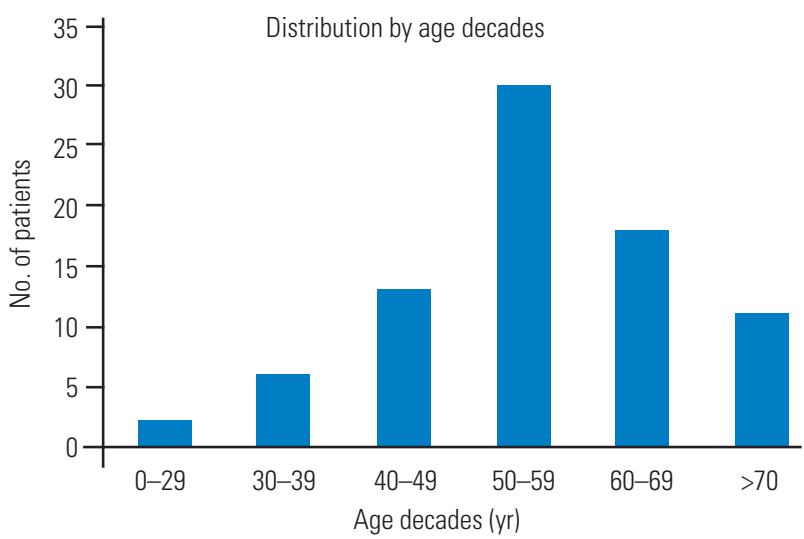

Fig. 1. Bar graph showing the distribution by age decades.

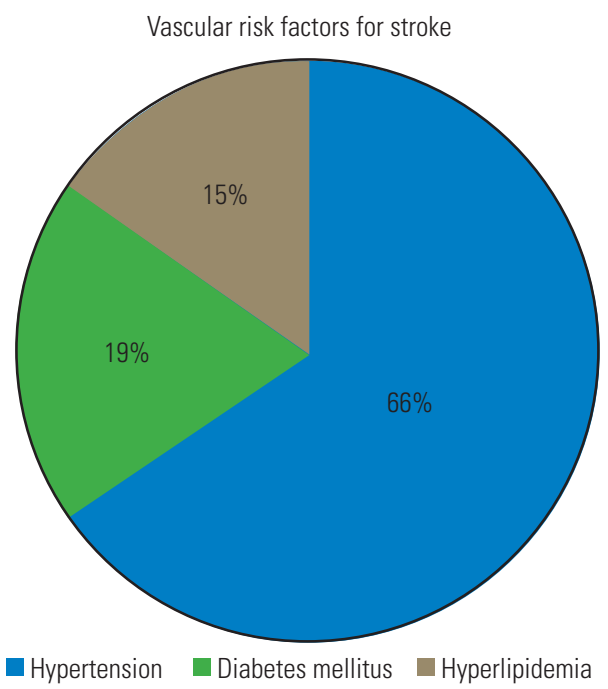

Fig. 2. Pie graph reporting the prevalence of the main vascular risk factors for stroke.

1 shows the distribution by age decades (Fig. 1). In cases with vascular risk factors for stroke, the average frequency of hypertension, diabetes mellitus, and hyperlipidemia were $66 \%, 19 \%$, and 15\%, respectively (Fig. 2). Dizziness, visual disturbances, and syncope had a prevalence rate of $76.8 \%, 50.4 \%$, and $40.4 \%$, respectively (Fig. 3). The C5 level was the most affected (31.4\%) followed by the C6 level (21.4\%) (Fig. 4). Left side had prevalence (33.9\% versus $31.4 \%$ ) and in $14.9 \%$ of the cases, the cause of occlusion involved both the sides (Fig. 5).

\section{Etiological factors}

Cervical spondylosis was the most common causative factor (46.2\%), followed by muscle band (33.8\%), fibrous perivascular ring (21.4\%), and disk herniations (7.4\%). Less com-

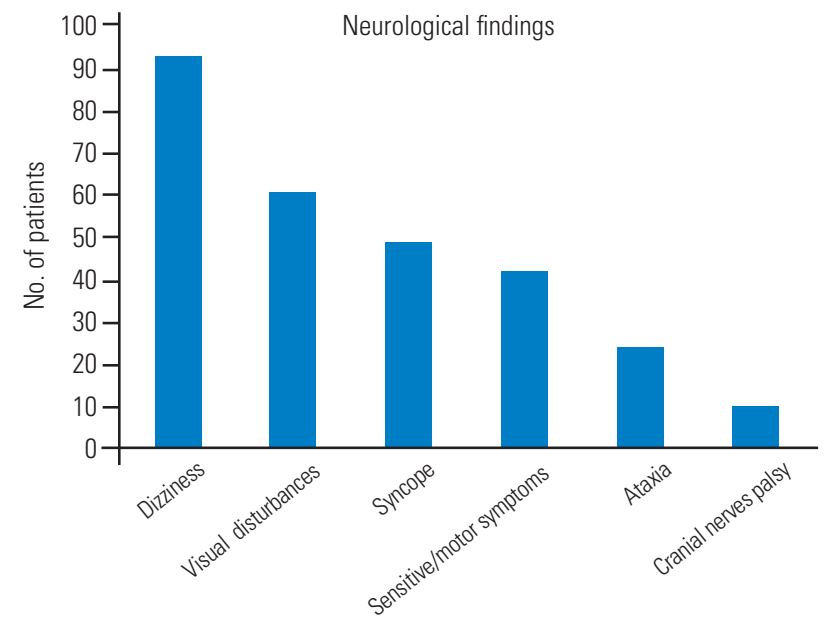

Fig. 3. Bar graph showing the main neurological findings.

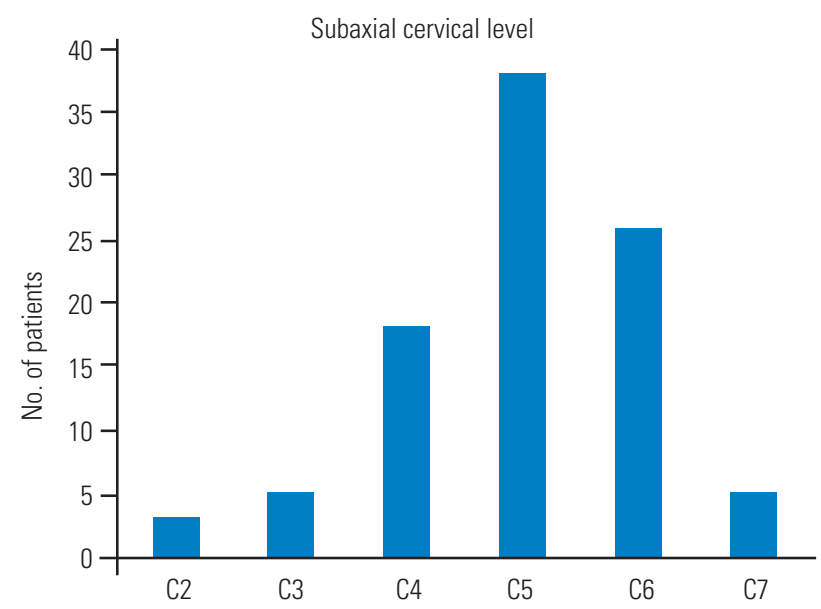

Fig. 4. Bar graph describing the rate of the involvement of the different subaxial cervical levels.

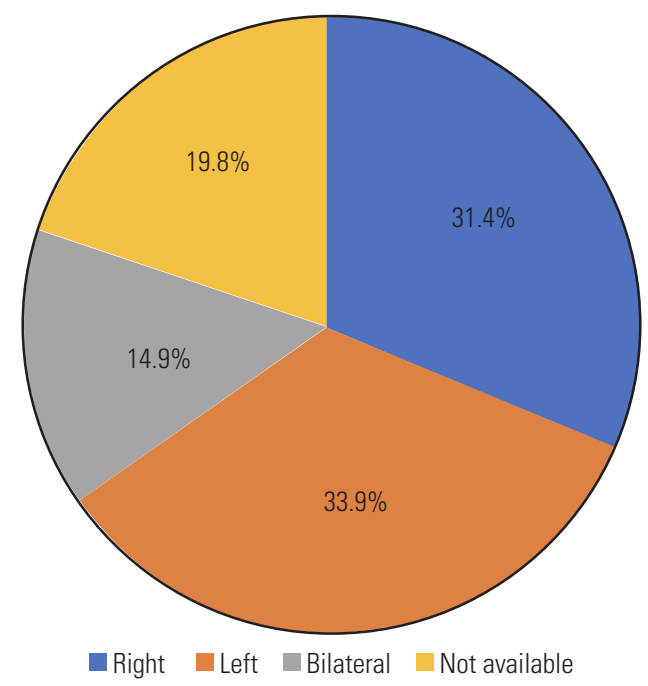

Fig. 5. Pie graph about the sideness. 


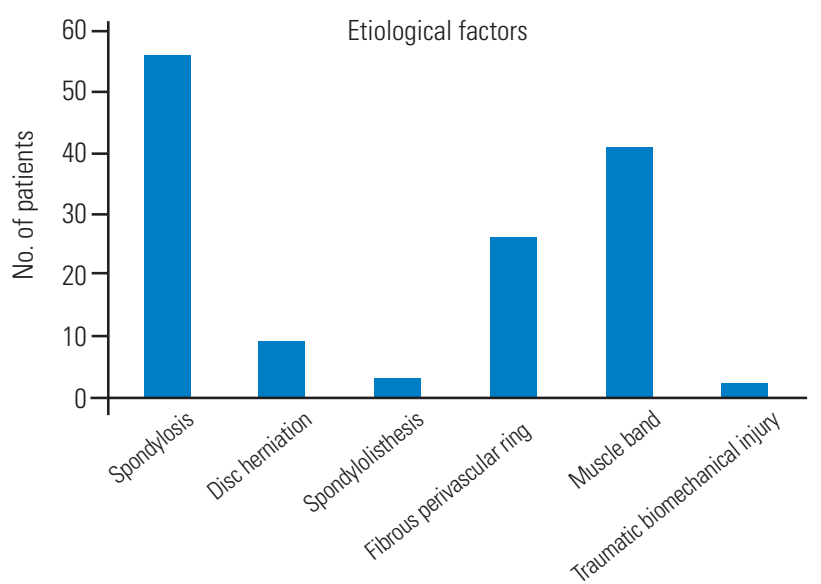

Fig. 6. Bar graph showing the prevalence of the different etiological factors.

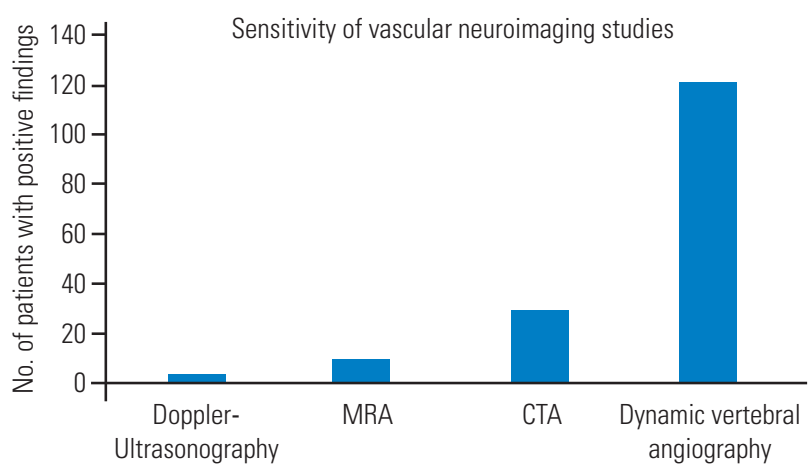

Fig. 7. Bar graph reporting the sensitivity of the vascular neuroimaging techniques. MRA, magnetic resonance angiography; CTA, computed tomography angiography.

mon reasons were degenerative spondylolisthesis (2.4\%) and biomechanical traumatic instability (1.6\%) (Fig. 6).

\section{Diagnostic work-up}

Diagnostic work-up involves different neurovascular imaging techniques whose sensitivity widely varies by type. Dynamic VA angiography, initially non-subtracted and then subtracted (digital subtraction angiography, DSA), has been crucial in the diagnosis in $100 \%$ of the reported cases. Computed tomography (CT) and magnetic resonance angiography were performed in $24.7 \%$ and $8.2 \%$ of the cases, respectively. Doppler ultrasound (DUS) standalone allowed the diagnosis in only four cases (3.3\%) [2426,32] (Fig. 7).

\section{Indication for surgery}

Considering the neuroimaging evidence of VA-ROS, the

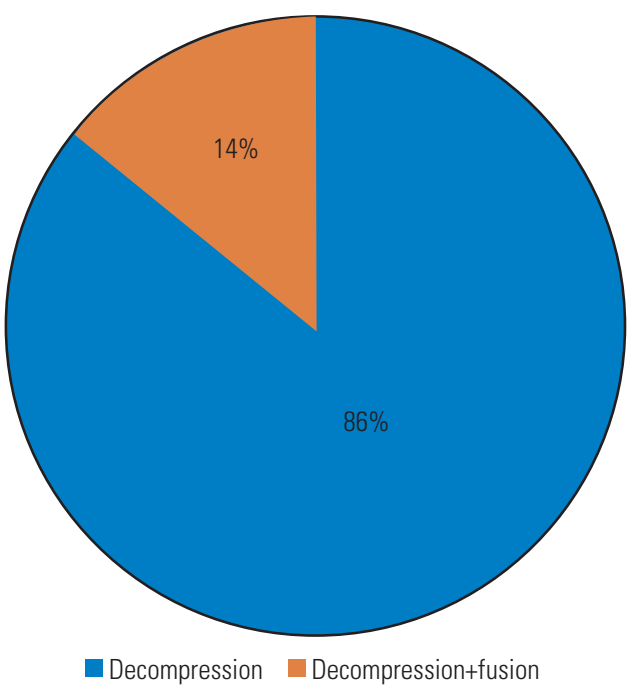

Fig. 8. Pie graph about the type of surgical treatment.

indication for surgery was based in all cases on the severity of the symptoms, negative impact on the performance of normal daily and working activities, and failure of conservative therapies. Conversely, conservative treatment in collar brace that also involved the establishment of an antiplatelet or anticoagulant therapy, to be decided case-bycase based on the coexistence of vascular risk factors for stroke, may have a rationale in elderly patients with minor symptoms.

\section{Choice of the approach and surgical corridors}

In all cases, anterior decompression of the VA was performed, accompanied by fusion in $16 \%$ of the cases (Fig. 8). An anterior Smith-Robinson (Baley-Cloward) approach was used in all cases with the exception of the series by George and Bruneau, where an anterolateral presternocleidomastoid retro-jugular route was reported [11,55-59].

\section{Complications}

No complications attributable to the surgical treatment have been reported, except in a case where the occurrence of Horner's syndrome suggested injury to the sympathetic chain [23].

\section{Overall outcome}

In $67 \%$ of the cases, the pre-operative symptoms disap- 
peared immediately after surgery, and vascular neuroimaging revealed a full release of the VA with no residual signs of extrinsic compression. Further, 22\% of the patients showed significant clinical improvement, while $11 \%$ reported only partial neurological amelioration with residual symptoms (Fig. 9). No specific scales were used for this evaluation.

\section{Illustrative case}

A 74-year-old male patient with medical history of hyper-

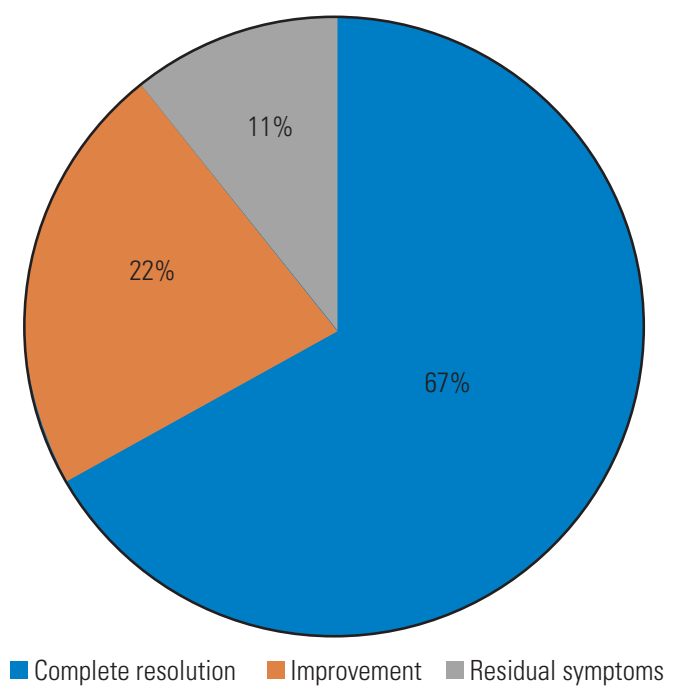

Fig. 9. Pie graph reporting the overall outcome.

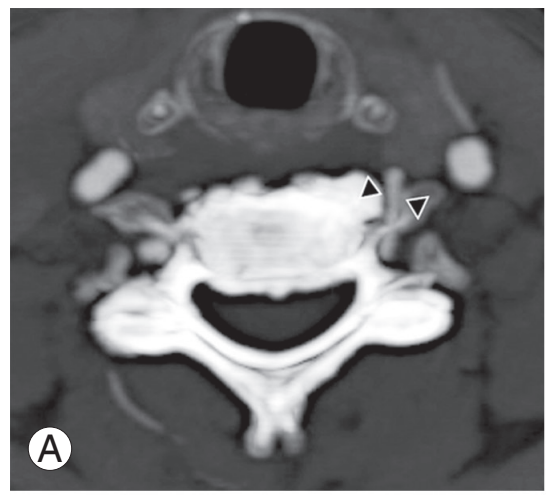

Fig. 10. Axial (A) and sagittal (B) contrast enhanced CT angiography showing a left C5-C6 margin-somatic osteophyte narrowing the near transverse foramen and causing a severe compression of the vertebral artery (arrowheads). tension experienced seven consecutive drop attacks in duration of 14 months. Cardiovascular investigations, blood tests for thrombophilia, and DUS were all within normal limits. The last attack was in association with left facial nerve palsy, rotatory nystagmus, dizziness, and numbness in the right arm. The CT and magnetic resonance imaging findings were normal; therefore, a transitory ischemic attack was suspected, and the patients underwent systemic thrombolysis, followed by anticoagulation with a factor Xa inhibitor, rivaroxaban. As the drop attacks manifested again in the 3 months after initiating anticoagulation therapy, the patients came to our attention. A comprehensive neurological examination revealed an association between the right axial rotation of the head $>45^{\circ}$ and early appearance of nausea, blurred vision, and dizziness. CT angiography revealed dynamic tethering of the VA at C5-C6 during right axial rotation of the head caused by a C6 osteophyte of the left uncinate process narrowing the anterior ramus of the satellite transverse foramen (Fig. 10). Catheter-based dynamic angiography confirmed these findings (Fig. 11). The patient underwent selective unroofing of the left C6 transverse foramen trough an anterolateral approach. The retro-longus colli corridor allowed easy reach and exposure of the subaxial portion of the V2 segment of the VA (Fig. 12). Postoperative static and dynamic CT and catheter-based angiography confirmed complete release of the VA (Fig. 13). The drop attacks subsided. Anticoagulant therapy was maintained for 1 month postoperatively and then discontinued.

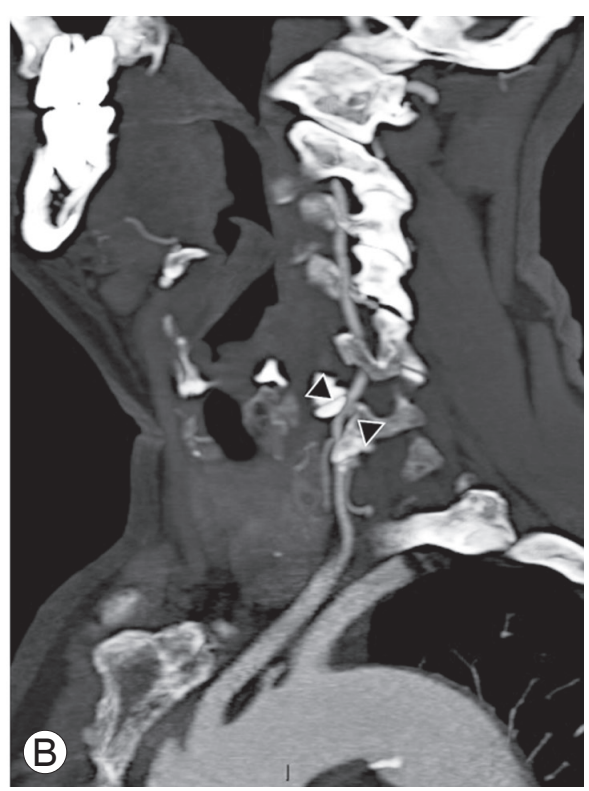



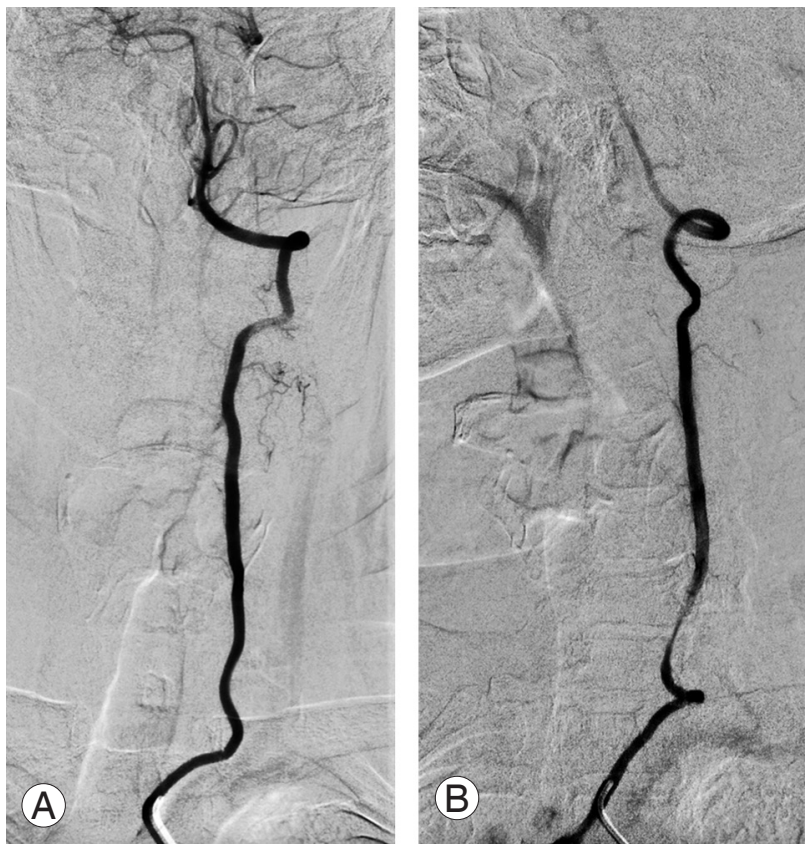

Fig. 11. Catheter-based digital subtraction angiography of the left vertebral artery. Static anterior-posterior projection (A) and dynamic right oblique projection (B) acquired during the right axial rotation of the head, and revealing a tethering of the vertebral artery at C6 level.

\section{Discussion}

The present comprehensive literature review about the management of the subaxial VA-ROS showed that most of the publications were case reports or small cases series. Dynamic angiography is the gold standard for this challenging diagnosis, and decompressive surgery performed via the anterior or anterolateral access route can be curative.

Based on a literature review, the biggest challenge concerning VA-ROS is the delay in diagnosis owing to the dynamic and intermittent nature of artery compression, thus often mimicking cardiovascular or other neurovascular pathologies. The transient symptomatology is caused by the axial rotation of the head during a careful neurologic evaluation. George et al. [60] reported that, paradoxically, chronic, static, and concentric causes of compressions, as those secondary to tumors abutting and slowly compressing the VA, are better tolerated because collateral muscular vascular supply develops to vicariate even occlusions of the dominant VA. From the clinical standpoint, compressions of the V2 segment are generally better tolerated than those of V1 and V3 owing to the protective role played
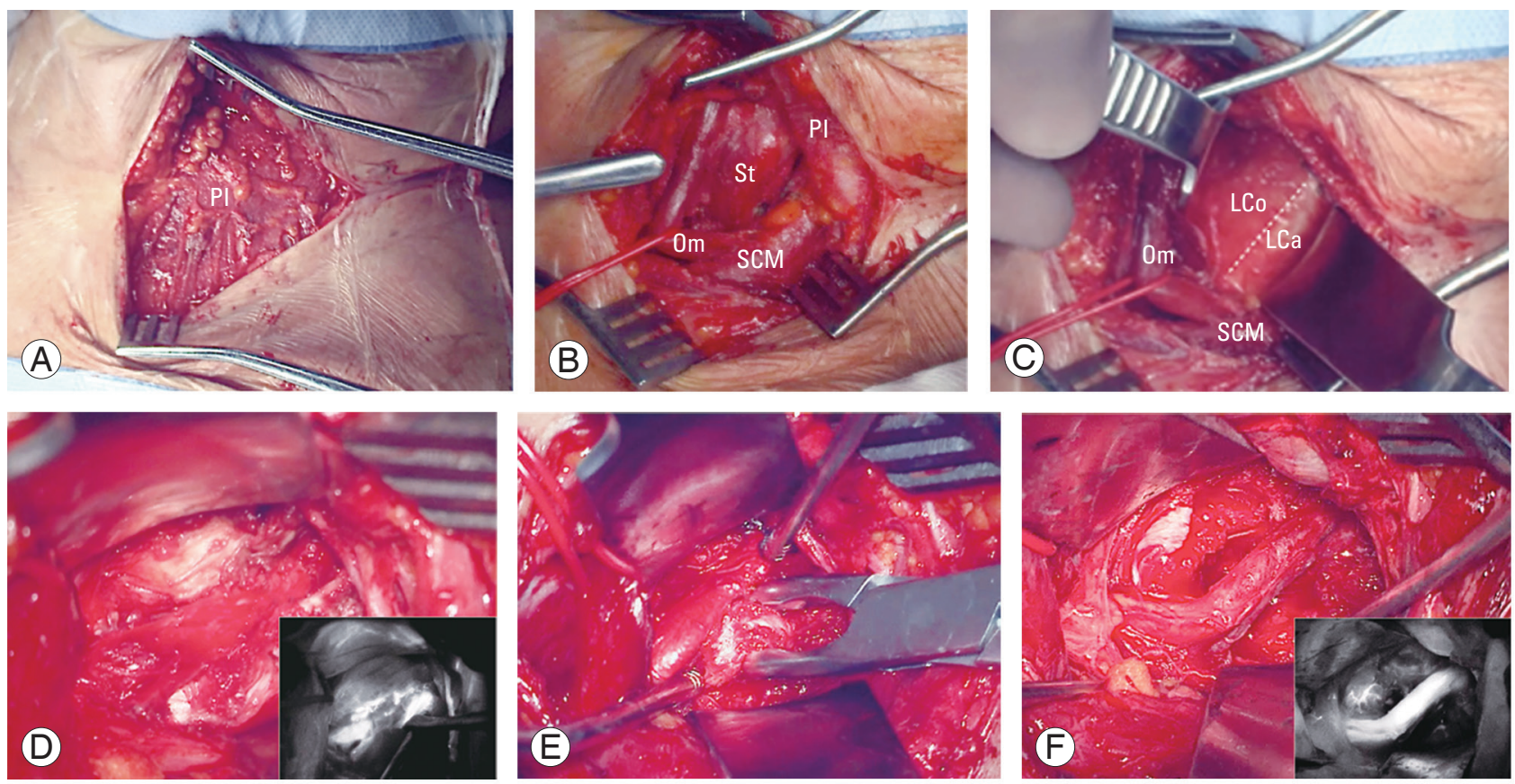

Fig. 12. Main surgical steps of the left anterolateral approach to the sub-axial V2 segment of the vertebral artery. (A) Platysma muscle; (B) pre-sternocleidomastoid precarotid corridor with medialization of the omohyoid muscle; (C) identification of the retro-longus colli corridor; (D) picture-in-picture operative image showing the compression of the vertebral artery by osteophyte and the indocyanine green video angiography (IR 800, Zeiss Kinevo 900; Carl Zeiss AG, Oberkochen, Germany); (E) unroofing of the left C6 transverse foramen. (F) Picture-in-picture operative picture and video angiography showing the vertebral artery completely decompressed. PI, platysma muscle; St, sternothyroid muscle; Om, omohyoid muscle; SCM, sternocleidomastoid muscle; LCo, longus colli muscle; LCa, longus capitis muscle. 

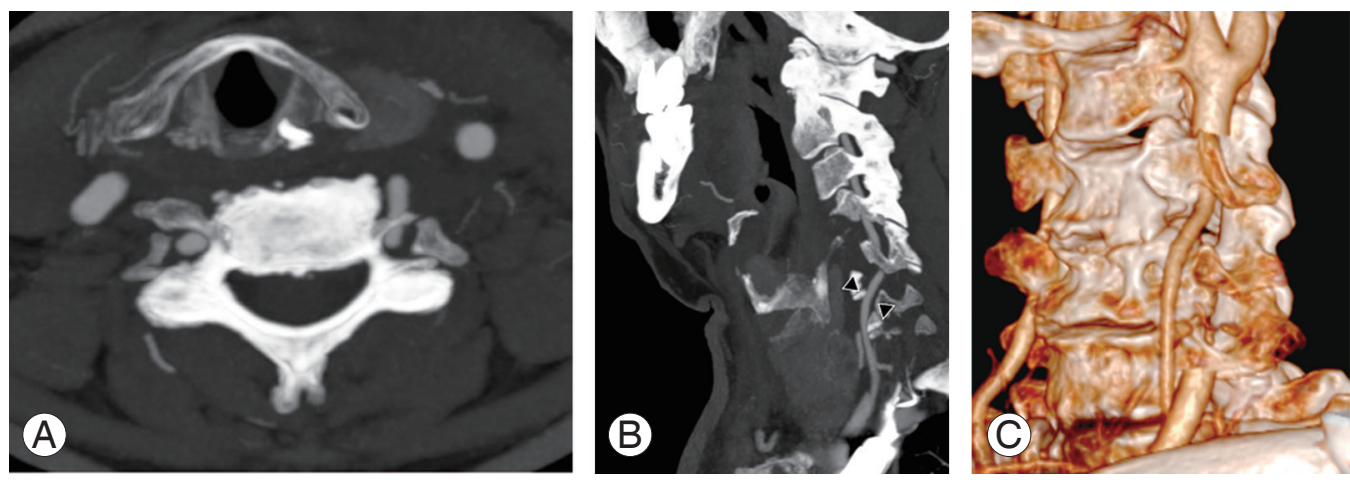

Fig. 13. Postoperative axial (A), sagittal (B) (arrowheads), and dynamic three-dimensional-rendered (C) computed tomography angiography of the vertebral artery revealing its complete release.

by the transverse processes. V1 is susceptible to compressions by fibrous bands and muscle fibers $[13,22,60]$, while $\mathrm{V} 3$ is the most commonly affected segment as pathology at the $\mathrm{CV}$ junction and $\mathrm{C} 1-\mathrm{C} 2$ is far more common [60].

In an extensive literature review on the pathophysiology and diagnosis of vertebrobasilar insufficiency, Lima Neto et al. [61] reported that this syndrome is more commonly observed in men after the fourth decade of life. Similar data have been reported by Savitz and Caplan [1].

Vertebrobasilar insufficiency is linked with three different mechanisms, including blood flow drop, embolic events, and autoregulation loss [3,60,62]. In particular, for the VA-ROS involving V2 in the subaxial cervical spine, osteophytes are the most common cause, and the embolization from thrombotic material secondary to a chronic sub adventitial mechanical stress seems responsible for the ischemic events [60].

Atherosclerosis is the most important coexisting condition favoring this syndrome; smoking, hypertension, hyperlipidemia, diabetes, and obesity are considered risk factors [61]. Not surprisingly, atrial fibrillation, infective endocarditis, and systemic hypercoagulable state further increase the stroke risk in VA-ROS patients.

Hence, the rationale of antiplatelet/anticoagulant regimen in those patients that not surgical candidates. Machaly et al. [63] demonstrated that vertigo is significantly more common in patients with severe forms of cervical spondylosis, while Olszewski et al. [64] documented a reduction in blood flow in the basilar artery and VAs that could be attributed to the extrinsic compression caused by osteophytes. Bulsara et al. [3] clarified that uncovertebral joint osteophytes cause symptoms during axial rotation and extension of the head, respectively.
Regarding those forms sustained by muscle and fibrous perivascular bands, male and younger patients are at a higher risk, with any probability because of the frequent muscular hypertonia.

Our data highlighted a major involvement of the C5 and C6 levels, similarly to that reported by Nagashima [19]. This subgroup of patients involved mostly men, and risk factors for atherosclerosis were present in all cases, thus confirming the aforementioned theory.

Labyrinthic symptoms associated with vertebrobasilar insufficiency are reported to be mainly caused by the lack of collateral vascular supply of the labyrinthine branches that are tiny and terminal in case of impairment of the vertebrobasilar arterial system $[1,61,65]$. Moubayed and Saliba [66] also postulated a possible direct ischemia of the labyrinth, secondary to peripheral hypoperfusion or ischemia.

The sensitivity of different neurovascular imaging techniques in the diagnosis of the subaxial VA-ROS warrants discussion. Although simple, non-invasive, repeatable and cost-effective, DUS had the worse sensitivity in our study. However, although it had a sensitivity lower than that of catheter-based angiography, dynamic CT angiography allows direct visualization of the bony compression on the VA, as well as its postoperative release. With a sensitivity and a specificity of $100 \%$, dynamic DSA remains the gold standard for the radiological diagnosis of the subaxial VAROS, allowing detailed appreciation of compression, but also giving information about vascular dominancy of one of the VAs, size of the posterior communicating arteries, anatomical variations of the VA at its termination in the posterior-inferior cerebellar artery, and existence of collaterals. With respect to the sensitivity and specificity of dy- 


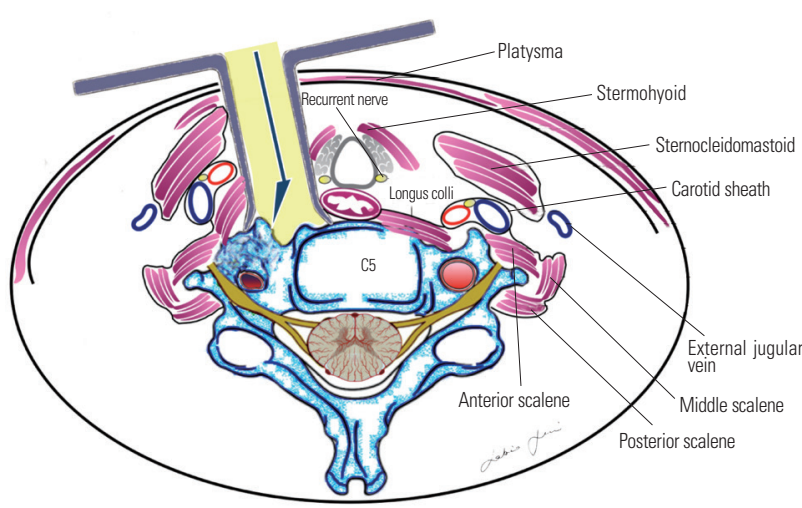

Fig. 14. Precarotid pre-longus colli corridor.

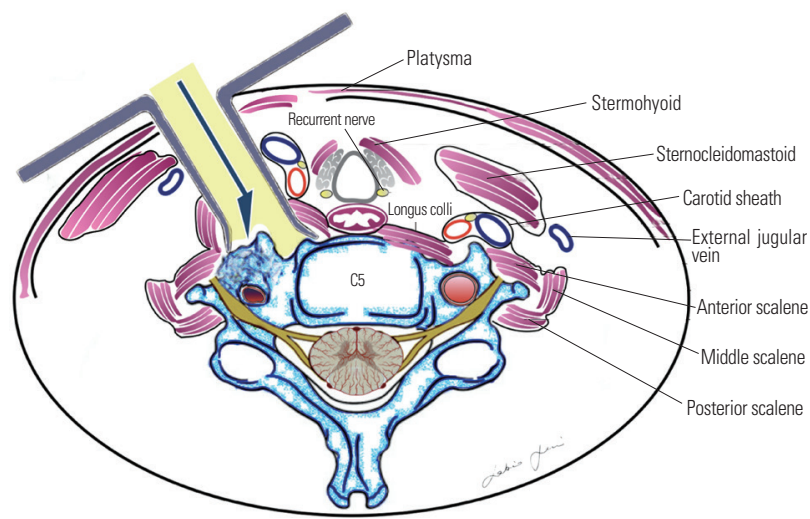

Fig. 15. Retro-jugular trans-longus colli corridor.

namic DSA, our data are consistent with those reported in the literature. It is noteworthy that Toole and Tucker [67] reported that in case of VAs that are different in size, the ischemic event may be attributable to the compression of the non-dominant VA after head rotation to the contralateral side. Selective catheterization of the VAs is obviously of utmost importance to confirm the diagnosis and for surgical planning.

Stand-alone surgical decompression, achieved with selective unroofing of the V2 segment of the VA at the transverse foramen, can be curative for subaxial VA-ROS of the V2 segment, if dynamic compression is demonstrated. In fact, our review demonstrated that the cumulative rate of complete recovery/improvement of symptoms is $89 \%$. For the remaining $11 \%$ of the patients with residual symptoms, we conducted an additional different decompressive technique for the removal of the so-called "fibrous band" if further impingement was noted at the V1 segment proximal to the artery entering the foramen at C6 [60].

The addition of a posterior instrumented fusion is sel-

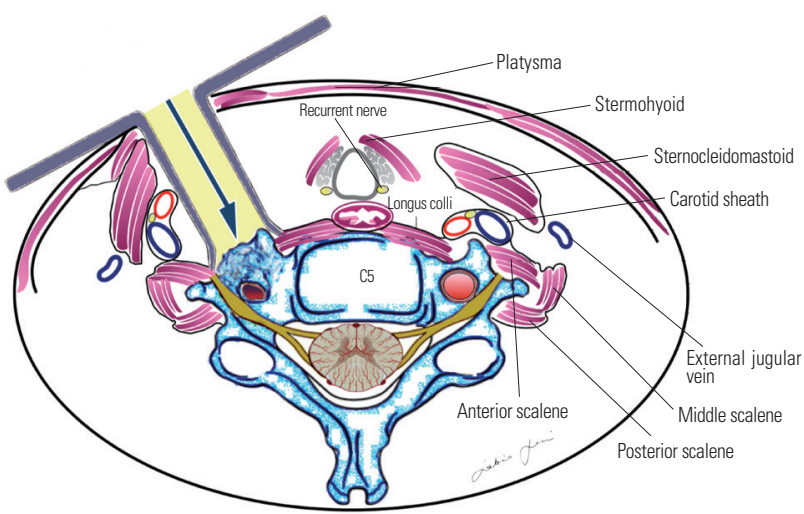

Fig. 16. Retro-longus colli corridor.

dom necessary and is necessary only if instability is noted or the compression is due to other causes, such as a disc herniation or spondylolisthesis $[11,24,25,34,44,48]$.

Most authors recommend simple lateral extension of the classic Smith-Robinson (Bailey-Cloward) technique [68-70] as suitable to expose the prevertebral musculature and VA $[13,14]$. This represents a routinely performed operation with which most neurosurgeons are familiar. The approach entails subperiosteal dissection of the longus colli muscle and the exposure of the anterior tubercle of the transverse foramen (Fig. 14). This approach is considered an anterior access route. An anterolateral approach was instead popularized by Bruneau et al. [10-12,57] to obtain an easier and more direct access to the subaxial V2 segment of the VA. The anterolateral approach involves a pre-sternocleidomastoid retro-jugular exposure of the prevertebral area along with the transection of the longus colli muscle (Fig. 15). As we report here in this illustrative case, we prefer the anterolateral approach for decompression of the subaxial VA with some modifications, including the precarotid exposure of the prevertebral muscles. The rationale of the precarotid exposure lies in the fact that injuries of the thoracic duct are very uncommon through this route because it has a more lateral course at the C4-C6 level [10,71-77] (Fig. 16).

Our personal experience also led us to delineated a retro-longus colli and a pre-scalenic prevertebral corridor for C5-C6 and C3-C4 level, respectively, to avoid injuries of the sympathetic chain and phrenic nerve, here having an upward and lateral-ward course [78-80] (Fig. 17).

Having the same advantages already reported by our group for aneurysms and arteriovenous malformations, intraoperative indocyanine green video angiography and microdoppler ultrasonography are also useful adjuncts 


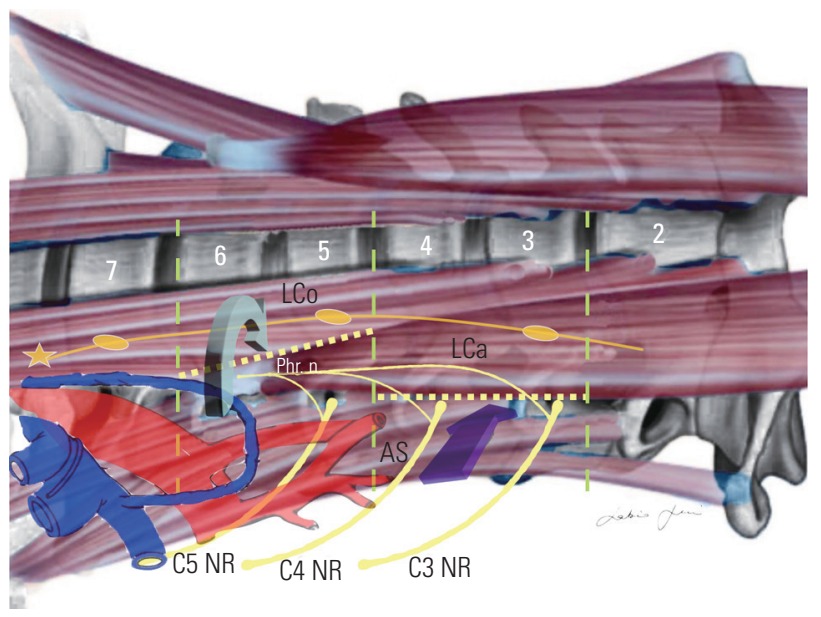

Fig. 17. Retro-longus colli (green arrow) and pre-scalenic (purple arrow) paramuscular corridor. Lco, longus colli muscle; Lca, longus capitis muscle; AS, anterior scalene muscle; Phr. n., phrenic nerve: NR, nerve root.

[81-88].

\section{Conclusions}

Subaxial VA-ROS classically causes drop attacks, dizziness, and visual disturbances triggered by axial rotation or head extension. A careful neurological evaluation is paramount to suspect the syndrome. Compressions of the V2 segment of the VA are caused in most cases by osteophytes that involve the uncoapophyseal joints at the C5 and C6 level. Compressions of the V1 segment of the artery relate to the presence of fibrous bands and muscular compression. Dynamic compressions of the VA by tumors are less common.

Dynamic DSA is the gold standard for establishing a diagnosis although dynamic CT angiography is the first step to delineate the extrinsic causes of compression. Anterior decompression of the subaxial VA affected segment is curative in most cases.

\section{Conflict of Interest}

No potential conflict of interest relevant to this article was reported.

\section{Acknowledgments}

We want to thank Eng. Giorgia Di Giusto for her outstanding and valuable support in formatting the manuscript and editing the graphs and figures.

\section{Author Contributions}

Conceptualization and writing-original draft preparation: Sabino Luzzi, Cristian Gragnaniello; software and validation: Stefano Marasco, Alice Giotta Lucifero; review and editing: Mattia Del Maestro; validation: Giuseppe Bellantoni; and supervision: Renato Galzio.

\section{References}

1. Savitz SI, Caplan LR. Vertebrobasilar disease. N Engl J Med 2005;352:2618-26.

2. Ujifuku K, Hayashi K, Tsunoda K, et al. Positional vertebral artery compression and vertebrobasilar insufficiency due to a herniated cervical disc. J Neurosurg Spine 2009;11:326-9.

3. Bulsara KR, Velez DA, Villavicencio A. Rotational vertebral artery insufficiency resulting from cervical spondylosis: case report and review of the literature. Surg Neurol 2006;65:625-7.

4. Sarkar J, Wolfe SQ, Ching BH, Kellicut DC. Bow hunter's syndrome causing vertebrobasilar insufficiency in a young man with neck muscle hypertrophy. Ann Vasc Surg 2014;28:1032.

5. Lee V, Riles TS, Stableford J, Berguer R. Two case presentations and surgical management of bow hunter's syndrome associated with bony abnormalities of the C7 vertebra. J Vasc Surg 2011;53:1381-5.

6. Johnson SA, Ducruet AF, Bellotte JB, Romero CE, Friedlander RM. Rotational vertebral artery dissection secondary to anomalous entrance into transverse foramen. World Neurosurg 2017;108:998.

7. Sparaco M, Ciolli L, Zini A. Posterior circulation ischaemic stroke-a review part I: anatomy, aetiology and clinical presentations. Neurol Sci 2019;40:19952006.

8. Morimoto T, Nakase H, Sakaki T, Matsuyama T. Extrinsic compression bow hunter's stroke. In: Bruneau M, Spetzler RF, George B, editors. Pathology and surgery around the vertebral artery. Paris: Springer; 2011. p. 473-87.

9. Sorensen BF. Bow hunter's stroke. Neurosurgery 1978;2:259-61.

10. Bruneau M, Cornelius JF, George B. Anterolateral approach to the V1 segment of the vertebral artery. Neurosurgery 2006;58(4 Suppl 2):ONS-215-9.

11. Bruneau M, Cornelius JF, George B. Anterolateral 
approach to the V2 segment of the vertebral artery. Neurosurgery 2005;57(4 Suppl):262-7.

12. Bruneau M, George B. The lateral approach to the V1 segment of the vertebral artery. In: Bruneau M, Spetzler RF, George B, editors. Pathology and surgery around the vertebral artery. Paris: Springer; 2011. p. 125-41.

13. Zaidi HA, Albuquerque FC, Chowdhry SA, Zabramski JM, Ducruet AF, Spetzler RF. Diagnosis and management of bow hunter's syndrome: 15-year experience at barrow neurological institute. World Neurosurg 2014;82:733-8.

14. Hakuba A. Trans-unco-discal approach: a combined anterior and lateral approach to cervical discs. J Neurosurg 1976;45:284-91.

15. Verbiest H. A lateral approach to the cervical spine: technique and indications. J Neurosurg 1968;28:191203.

16. Gortvai P. Insufficiency of vertebral artery treated by decompression of its cervical part. Br Med J 1964;2:233-4.

17. Hardin CA. Vertebral artery insufficiency produced by cervical osteoarthritic spurs. Arch Surg 1965;90:629-33.

18. Bakay L, Leslie EV. Surgical treatment of vertebral artery insufficiency caused by cervical spondylosis. J Neurosurg 1965;23:596-602.

19. Nagashima C. Surgical treatment of vertebral artery insufficiency caused by cervical spondylosis. J Neurosurg 1970;32:512-21.

20. Smith DR, Vanderark GD, Kempe LG. Cervical spondylosis causing vertebrobasilar insufficiency: a surgical treatment. J Neurol Neurosurg Psychiatry 1971;34:388-92.

21. Sullivan HG, Harbison JW, Vines FS, Becker D. Embolic posterior cerebral artery occlusion secondary to spondylitic vertebral artery compression: case report. J Neurosurg 1975;43:618-22.

22. Mapstone T, Spetzler RF. Vertebrobasilar insufficiency secondary to vertebral artery occlusion froma fibrous band: case report. J Neurosurg 1982;56:581-3.

23. Kawaguchi T, Fujita S, Hosoda K, Shibata Y, Iwakura M, Tamaki N. Rotational occlusion of the vertebral artery caused by transverse process hyperrotation and unilateral apophyseal joint subluxation: case report. J Neurosurg 1997;86:1031-5.

24. Vates GE, Wang KC, Bonovich D, Dowd CF, Law- ton MT. Bow hunter stroke caused by cervical disc herniation: case report. J Neurosurg 2002;96(1 Suppl):90-3.

25. Nemecek AN, Newell DW, Goodkin R. Transient rotational compression of the vertebral artery caused by herniated cervical disc: case report. J Neurosurg 2003;98(1 Suppl):80-3.

26. Vilela MD, Goodkin R, Lundin DA, Newell DW. Rotational vertebrobasilar ischemia: hemodynamic assessment and surgical treatment. Neurosurgery 2005;56:36-45.

27. Tsutsumi S, Ito M, Yasumoto Y. Simultaneous bilateral vertebral artery occlusion in the lower cervical spine manifesting as bow hunter's syndrome. Neurol Med Chir (Tokyo) 2008;48:90-4.

28. Lu DC, Zador Z, Mummaneni PV, Lawton MT. Rotational vertebral artery occlusion-series of 9 cases. Neurosurgery 2010;67:1066-72.

29. Yoshimura K, Iwatsuki K, Ishihara M, Onishi Y, Umegaki M, Yoshimine T. Bow hunter's stroke due to instability at the uncovertebral C3/4 joint. Eur Spine J 2011;20 Suppl 2(Suppl 2):S266-70.

30. Pinol I, Ramirez M, Salo G, Ros AM, Blanch AL. Symptomatic vertebral artery stenosis secondary to cervical spondylolisthesis. Spine (Phila Pa 1976) 2013;38:E1503-5.

31. Fleming JB, Vora TK, Harrigan MR. Rare case of bilateral vertebral artery stenosis caused by C4-5 spondylotic changes manifesting with bilateral bow hunter's syndrome. World Neurosurg 2013;79:799.

32. Buchanan CC, McLaughlin N, Lu DC, Martin NA. Rotational vertebral artery occlusion secondary to adjacent-level degeneration following anterior cervical discectomy and fusion. J Neurosurg Spine 2014;20:714-21.

33. Healy AT, Lee BS, Walsh K, Bain MD, Krishnaney AA. Bow hunter's syndrome secondary to bilateral dynamic vertebral artery compression. J Clin Neurosci 2015;22:209-12.

34. Okawa M, Amamoto T, Abe H, Yoshimura S, Higashi $\mathrm{T}$, Inoue $\mathrm{T}$. Wake-up stroke in a young woman with rotational vertebral artery occlusion due to farlateral cervical disc herniation. J Neurosurg Spine 2015;23:166-9.

35. Jost GF, Dailey AT. Bow hunter's syndrome revisited: 2 new cases and literature review of 124 cases. Neurosurg Focus 2015;38:E7. 
36. Nishikawa H, Miya F, Kitano Y, Mori G, Shimizu S, Suzuki H. Positional occlusion of vertebral artery due to cervical spondylosis as rare cause of wakeup stroke: report of two cases. World Neurosurg 2017;98:877.

37. Iida Y, Murata H, Johkura K, Higashida T, Tanaka T, Tateishi K. Bow hunter's syndrome by nondominant vertebral artery compression: a case report, literature review, and significance of downbeat nystagmus as the diagnostic clue. World Neurosurg 2018;111:36772.

38. Cornelius JF, Slotty PJ, Tortora A, Petridis AK, Steiger HJ, George B. Bow hunter's syndrome caused by compression of the subaxial vertebral artery: surgical technique of anterolateral decompression (video). World Neurosurg 2018;119:358-61.

39. Schunemann V, Kim J, Dornbos D 3rd, Nimjee SM. C2-C3 anterior cervical arthrodesis in the treatment of bow hunter's syndrome: case report and review of the literature. World Neurosurg 2018;118:284-9.

40. Ng S, Boetto J, Favier V, Thouvenot E, Costalat V, Lonjon N. Bow hunter's syndrome: surgical vertebral artery decompression guided by dynamic intraoperative angiography. World Neurosurg 2018;118:290-5.

41. Powers SR Jr, Drislane TM, Nevins S. Intermittent vertebral artery compression; a new syndrome. Surgery 1961;49:257-64.

42. Husni EA. Mechanical occlusion of the vertebral artery. GP 1967;35:94-8.

43. Dadsetan MR, Skerhut HE. Rotational vertebrobasilar insufficiency secondary to vertebral artery occlusion from fibrous band of the longus coli muscle. Neuroradiology 1990;32:514-5.

44. Budway RJ, Senter HJ. Cervical disc rupture causing vertebrobasilar insufficiency. Neurosurgery 1993;33:745-7.

45. Chin JH. Recurrent stroke caused by spondylotic compression of the vertebral artery. Ann Neurol 1993;33:558-9.

46. Kuether TA, Nesbit GM, Clark WM, Barnwell SL. Rotational vertebral artery occlusion: a mechanism of vertebrobasilar insufficiency. Neurosurgery 1997;41:427-33.

47. Citow JS, Macdonald RL. Posterior decompression of the vertebral artery narrowed by cervical osteophyte: case report. Surg Neurol 1999;51:495-9.

48. Kimura T, Sako K, Tohyama Y, Hodozuka A. Bow hunter's stroke caused by simultaneous occlusion of both vertebral arteries. Acta Neurochir (Wien) 1999;141:895-6.

49. Ogino M, Kawamoto T, Asakuno K, Maeda Y, Kim P. Proper management of the rotational vertebral artery occlusion secondary to spondylosis. Clin Neurol Neurosurg 2001;103:250-3.

50. Velat GJ, Reavey-Cantwell JF, Ulm AJ, Lewis SB. Intraoperative dynamic angiography to detect resolution of bow hunter's syndrome: technical case report. Surg Neurol 2006;66:420-3.

51. Miele VJ, France JC, Rosen CL. Subaxial positional vertebral artery occlusion corrected by decompression and fusion. Spine (Phila Pa 1976) 2008;33:E36670.

52. Dargon PT, Liang CW, Kohal A, Dogan A, Barnwell SL, Landry GJ. Bilateral mechanical rotational vertebral artery occlusion. J Vasc Surg 2013;58:1076-9.

53. Haimoto S, Nishimura Y, Hara M, et al. Surgical Treatment of rotational vertebral artery syndrome induced by spinal tumor: a case report and literature review. NMC Case Rep J 2017;4:101-5.

54. Rendon R, Mannoia K, Reiman S, Hitchman L, Shutze W. Rotational vertebral artery occlusion secondary to completely extraosseous vertebral artery. J Vasc Surg Cases Innov Tech 2018;5:14-7.

55. Bruneau M, Cornelius JF, George B. Microsurgical cervical nerve root decompression by anterolateral approach. Neurosurgery 2006;58(1 Suppl):ONS108-13.

56. Bruneau M, Cornelius JF, George B. The selective microforaminotomy. In: Bruneau M, Spetzler RF, George B, editors. Pathology and surgery around the vertebral artery. Paris: Springer; 2011. p. 227-46.

57. Bruneau M, George B. The lateral approach to the V2 segment of the vertebral artery. In: Bruneau $M$, Spetzler RF, George B, editors. Pathology and surgery around the vertebral artery. Paris: Springer; 2011. p. 143-64.

58. George B, Laurian C. Surgical approach to the whole length of the vertebral artery with special reference to the third portion. Acta Neurochir (Wien) 1980;51:259-72.

59. George B, Lot G. Neurinomas of the first two cervical nerve roots: a series of 42 cases. J Neurosurg 1995;82:917-23.

60. George B, Bresson D, Bruneau M. Extrinsic compres- 
sion of the vertebral artery. In: Bruneau M, Spetzler RF, George B, editors. Pathology and surgery around the vertebral artery. Paris: Springer; 2011. p. 273-83.

61. Lima Neto AC, Bittar R, Gattas GS, et al. Pathophysiology and diagnosis of vertebrobasilar insufficiency: a review of the literature. Int Arch Otorhinolaryngol 2017;21:302-7.

62. Mitchell JA. Changes in vertebral artery blood flow following normal rotation of the cervical spine. J Manipulative Physiol Ther 2003;26:347-51.

63. Machaly SA, Senna MK, Sadek AG. Vertigo is associated with advanced degenerative changes in patients with cervical spondylosis. Clin Rheumatol 2011;30:1527-34.

64. Olszewski J, Majak J, Pietkiewicz P, Luszcz C, Repetowski $\mathrm{M}$. The association between positional vertebral and basilar artery flow lesion and prevalence of vertigo in patients with cervical spondylosis. Otolaryngol Head Neck Surg 2006;134:680-4.

65. Gomez CR, Cruz-Flores S, Malkoff MD, Sauer CM, Burch CM. Isolated vertigo as a manifestation of vertebrobasilar ischemia. Neurology 1996;47:94-7.

66. Moubayed SP, Saliba I. Vertebrobasilar insufficiency presenting as isolated positional vertigo or dizziness: a double-blind retrospective cohort study. Laryngoscope 2009;119:2071-6.

67. Toole JF, Tucker SH. Influence of head position upon cerebral circulation: studies on blood flow in cadavers. Arch Neurol 1960;2:616-23.

68. Bailey RW, Badgley CE. Stabilization of the cervical spine by anterior fusion. J Bone Joint Surg Am 1960;42-A:565-94.

69. Robinson RA, Smith GW. Anterolateral cervical disc removal and interbody fusion for cervical disc syndrome. SAS J 2010;4:34-5.

70. Cloward RB. The anterior approach for removal of ruptured cervical disks. J Neurosurg 1958;15:602-17.

71. Kawashima M, Tanriover N, Rhoton AL Jr, Matsushima T. The transverse process, intertransverse space, and vertebral artery in anterior approaches to the lower cervical spine. J Neurosurg 2003;98(2 Suppl):188-94.

72. Hart AK, Greinwald JH Jr, Shaffrey CI, Postma GN. Thoracic duct injury during anterior cervical discectomy: a rare complication: case report. J Neurosurg 1998;88:151-4.

73. Davis HK. A statistical study of the thoracic duct in man. Am J Anat 1915;17:211-44.

74. Gottlieb MI, Greenfield J. Variations in the terminal portion of the human thoracic duct. AMA Arch Surg 1956;73:955-9.

75. Kinnaert P. Anatomical variations of the cervical portion of the thoracic duct in man. J Anat 1973;115(Pt 1):45-52.

76. Van Pernis PA. Variations of the thoracic duct. Surgery 1949;26:806-9.

77. Ammar K, Tubbs RS, Smyth MD, et al. Anatomic landmarks for the cervical portion of the thoracic duct. Neurosurgery 2003;53:1385-8.

78. Kiray A, Arman C, Naderi S, Guvencer M, Korman E. Surgical anatomy of the cervical sympathetic trunk. Clin Anat 2005;18:179-85.

79. Ebraheim NA, Lu J, Yang H, Heck BE, Yeasting RA. Vulnerability of the sympathetic trunk during the anterior approach to the lower cervical spine. Spine (Phila Pa 1976) 2000;25:1603-6.

80. Lyons AJ, Mills CC. Anatomical variants of the cervical sympathetic chain to be considered during neck dissection. Br J Oral Maxillofac Surg 1998;36:180-2.

81. Ricci A, Di Vitantonio H, De Paulis D, et al. Cortical aneurysms of the middle cerebral artery: a review of the literature. Surg Neurol Int 2017;8:117.

82. Del Maestro M, Luzzi S, Gallieni M, et al. Surgical treatment of arteriovenous malformations: role of preoperative staged embolization. Acta Neurochir Suppl 2018;129:109-13.

83. Gallieni M, Del Maestro M, Luzzi S, Trovarelli D, Ricci A, Galzio R. Endoscope-assisted microneurosurgery for intracranial aneurysms: operative technique, reliability, and feasibility based on 14 years of personal experience. Acta Neurochir Suppl 2018;129:19-24.

84. Luzzi S, Del Maestro M, Bongetta D, et al. Onyx Embolization before the surgical treatment of Grade III Spetzler-Martin brain arteriovenous malformations: single-center experience and technical nuances. World Neurosurg 2018;116:e340-53.

85. Luzzi S, Gallieni M, Del Maestro M, Trovarelli D, Ricci A, Galzio R. Giant and very large intracranial aneurysms: surgical strategies and special issues. Acta Neurochir Suppl 2018;129:25-31.

86. Luzzi S, Del Maestro M, Galzio R. Letter to the editor: preoperative embolization of brain arteriovenous malformations. J Neurosurg 2019:1-2. 
87. Luzzi S, Elia A, Del Maestro M, et al. Indication, timing, and surgical treatment of spontaneous intracerebral hemorrhage: systematic review and proposal of a management algorithm. World Neurosurg 2019:S1878-8750(19)30105-6.
88. Luzzi S, Del Maestro M, Elbabaa SK, Galzio R. Letter to the editor regarding "one and done: multimodal treatment of pediatric cerebral arteriovenous malformations in a single anesthesia event". World Neurosurg 2020;134:660. 